\title{
BMJ Open The stability of weight status through the early to middle childhood years in Australia: a longitudinal study
}

\author{
Nikita Wheaton, Lynne Millar, Steven Allender, Melanie Nichols
}

To cite: Wheaton N, Millar L, Allender S, et al. The stability of weight status through the early to middle childhood years in Australia: a longitudinal study. BMJ Open 2015;5:e006963. doi:10.1136/bmjopen-2014006963

- Prepublication history for this paper is available online. To view these files please visit the journal online (http://dx.doi.org/10.1136/ bmjopen-2014-006963).

Received 21 October 2014 Revised 17 February 2015 Accepted 26 February 2015

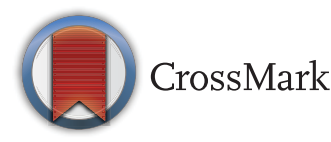

Faculty of Health, WHO Collaborating Centre for Obesity Prevention, Deakin University, Geelong, Australia

Correspondence to Nikita Wheaton; n.wheaton@research.deakin. edu.au

\section{ABSTRACT}

Objectives: To investigate the sociodemographic and behavioural factors associated with incidence, persistence or remission of obesity in a longitudinal sample of Australian children aged 4-10 years.

Setting: Nationally representative Longitudinal Study of Australian Children (LSAC).

Participants: The sample for this analysis included all children in the Kinder cohort (aged 4-5 years at wave 1 ) who participated in all four waves of LSAC (wave 1, 2004, aged 4-5 years; wave 2, 2006, aged 6-7 years; wave 3, 2008, aged 8-9 years and wave 4, 2010, aged 10-11 years). Of the 4983 children who participated in the baseline (wave 1) survey, $4169(83.7 \%)$ children completed all four waves of data collection.

\section{Primary and secondary outcome measures:}

Movement of children between weight status categories over time and individual-level predictors of weight status change (sociodemographic characteristics, selected dietary and activity behaviours).

Results: The study found tracking of weight status across this period of childhood. There was an inverse association observed between socioeconomic position and persistence of overweight/obesity. Sugarsweetened beverages and fruit and vegetable intake and screen time appeared to be important predictors of stronger tracking.

Conclusions: Overweight and obesity established early in childhood tracks strongly to the middle childhood years in Australia, particularly among children of lower socioeconomic position and children participating in some unhealthy behaviour patterns.

\section{INTRODUCTION}

Childhood obesity is maintained (tracks) into adulthood ${ }^{1}{ }^{2}$ and represents a strong contribution to the burden of ill health throughout adolescence and adulthood. ${ }^{3}$ Risk for obesity at any one time among children and adults is relatively well understood to include behavioural and socioeconomic factors including sedentary behaviour, ${ }^{45}$ diet and sugar-sweetened beverages (SSB), ${ }^{6-8}$ high calorie, nutrient-poor snack foods ${ }^{9}$ and low fruit and vegetable consumption. ${ }^{9}$ These
Strengths and limitations of this study

- The major strength of this research is that the data are drawn from four recent waves of a large, nationally representative Iongitudinal cohort of Australian children. The study used high-quality, reliable data collection methods for anthropometric measures, which were collected in person by trained personnel according to best practice protocols.

- Further, the study had a high retention rate of participants. Of the 4983 children who participated in the baseline (wave 1) survey, 4169 children completed all four waves of data collection, representing an attrition rate of just $16.3 \%$ over 6 years.

- Body mass index-based reference standards were used to determine weight status, which may have misclassified some children, especially those who have less severe overweight.

- Children from disadvantaged areas, non-English speaking backgrounds and single-parent families are somewhat under-represented in the Longitudinal Study of Australian Children (LSAC) cohort, while there was an over-representation of children with mothers with higher education levels (those who had completed year 12 education).

- There are also a number of difficulties surrounding data collection in relation to diet and activity behaviours and limitations to the accuracy and reliability of reporting, and $24 \mathrm{~h}$ recall data may not represent usual behaviour. The dietary indicators in particular offered a relatively crude representation of consumption patterns. Further, the physical activity information data collected in the LSAC was insufficient to be used in these analyses; therefore, no adjustment of dietary intake for energy expenditure could be made. This may explain the apparently anomalous association of increased fruit and vegetable consumption with tracking.

risks are mediated by individual factors including age, gender, ethnicity and socioeconomic position (SEP)..$^{10-13}$

The degree of tracking of overweight and obesity through childhood is inconsistent and the association between tracking and 
sociodemographic and behavioural factors is uncertain. Tracking has been shown to be high among Canadian and American children; overweight boys and girls aged 2-5 years were $>4$ times as likely to become overweight adults (aged 37 years), compared with their normalweight peers. ${ }^{14}$ Similarly, in a longitudinal analysis of Flemish females, $64 \%$ of overweight adolescent girls (mean age 16.6 \pm 1.1 years) remained overweight in adulthood (mean age $=40.5 \pm 1.1$ years) ${ }^{15}$ In an Indonesian longitudinal study measuring the body mass index (BMI) of 308 children aged 6-8 years (mean follow-up $5.1 \pm 0.6$ years), childhood BMI determined $52.3 \%$ of the variation in later BMI. ${ }^{16}$

An Australian study found that among children aged 5-10 years, overweight and obesity prevalence increased between baseline (15\% overweight, $4.3 \%$ obese) and follow-up ( $19.7 \%$ overweight, $4.8 \%$ obese), mean time between baseline and follow-up $3.2 \pm 0.2$ years. ${ }^{17}$ Of the 438 children, there were 140 incident cases of overweight $(9.7 \%), 24$ incident cases of obesity $(1.7 \%)$ and only $3.8 \%$ of the cohort resolving to a healthier weight status, while $66.2 \%$ of children who were overweight and $72.6 \%$ who were obese at baseline remained in that category at follow-up. ${ }^{17}$ This study was only representative of the state of Victoria, Australia with a relatively short follow-up time (3.2 \pm 0.2 years), but it provides important preliminary evidence to support further investigations into the patterns of overweight and obesity maintenance, incidence and remission nationally.

To gain an understanding of the Australian context, it is important to examine the stability of children's weight status using longitudinal data in a high-quality and representative sample and, moreover, to investigate the sociodemographic and behavioural factors associated with persistence or remission of obesity, or with incident obesity. This will provide important evidence about Australian children's weight trajectories and the factors associated with becoming, staying or ceasing being overweight, ultimately influencing population obesity prevention and management strategies for children.

In this study, we set out to address the following research question:

"What factors influence the stability of weight status through early to middle childhood (between the ages of 4 and 10 years) in Australia?"

\section{METHODS}

\section{Study population}

Data used in this analysis were from the Longitudinal Study of Australian Children (LSAC), which is a continuing nationally representative longitudinal survey study that aims to observe Australian children's development and well-being and examine links with social, economic and cultural aspects of their environment. ${ }^{18}$ The children were identified through the Medicare Australia enrolments database which contains the majority of Australian children's details. In 2004, >18 000 children were sampled from this database $(0-1$ years, the Birth or 'B' cohort; 4-5 years, Kinder or ' $\mathrm{K}$ ' cohort) ${ }^{18}$ The data were collected using a two stage clustered design; first selecting postcodes and then children. Stratification was used to ensure that proportionate numbers of children were selected to represent states and territories as well as representation from cities as well as rural and remote areas. Data are collected in a series of 'waves' that are collected biennially, as well as mail-out data collections that occur between waves.

The sample for this analysis included all children in the K-cohort (aged 4-5 years at wave 1 ) who participated in all four waves of LSAC (wave 1, 2004, aged 4-5 years; wave 2, 2006, aged 6-7 years; wave 3, 2008, aged 8-9 years and wave 4,2010 , aged 10-11 years). Of the 4983 children who participated in the baseline (wave 1) survey, $4169(83.7 \%)$ completed all four waves of data collection; of these children, 223 had some missing data at random for at least one wave.

\section{Measures}

Data from the LSAC study included in this analysis were:

\section{Anthropometric measures}

Children's weight was measured in light clothing to the nearest $50 \mathrm{~g}$ using glass bathroom scales (Salter Australia, Code 79985; Springvale, Victoria, Australia) and height to the nearest $0.1 \mathrm{~cm}$ by trained data collectors using a portable rigid stadiometer (Invicta, (Leicester, UK), Model IPO955). The averages of two height measures were used; where the two differed by greater than $0.5 \mathrm{~cm}$, a third measurement was obtained and the average of the two closest was used. ${ }^{19}$

Parent self-reports of their height and weight were collected. Instead of collecting height and weight information during the face-to-face interview, each parent self-reported these data as part of a leave-behind questionnaire.

\section{Sociodemographic variables}

Ethnicity (wave 1): A range of indicators of ethnicity were reported by parents in wave 1 of LSAC during the face-to-face interview. Indicators that were included in the analysis include: (1) 'In which country was Parent 1 born?' (2) 'In which country was Parent 2 born?' (3) 'In which country was Study Child born?' and (4) 'Does Study Child speak a language other than English at home?'

SEP. The LSAC composite household SEP variable was constructed by Blakemore et $a l^{20}{ }^{20}$ and was derived from standardised scores for: combined annual household income; parents' years of education; and parents' occupations. The summary measure of SEP developed for each family produced a continuous score.

\section{Behavioural variables}

Diet: Three dietary variables were analysed in this study; SSB, high-fat foods (HFF) and fruit and vegetable consumption. SSB and HFF are derived variables which are 
provided in the LSAC data set. The stem question for all food and drink items was identical, "In the last $24 \mathrm{~h}$ has your child had the following foods or drinks once, more than once or not at all?"

Intake of SSBs was measured by two parent-reported survey questions, indicating the consumption frequency of: (1) fruit juice; (2) soft drink or cordial (not diet), in the $24 \mathrm{~h}$ prior to the survey.

Intake of HFFs was measured similarly using four questions. The questions sought information on the frequency of consumption of (1) meat pie, hamburger, hot dog, sausage or sausage roll; (2) hot chips or french fries; (3) potato chips or savoury snacks such as 'Twisties'; and (4) biscuits, doughnuts, cake, pie or chocolate in the $24 \mathrm{~h}$ prior to the survey. Responses were summed and a final score for frequency of SSB and HFF consumption was assigned.

In waves 1, 2 and 3, fruit and vegetable consumption was reported by parent 1 during the face-to-face interview. The three questions asked were, 'In the last $24 \mathrm{~h}$ how often did the study child eat (1) fresh fruit, (2) cooked vegetables and (3) raw vegetables or salad?' Frequency was coded 0 for 'not at all', 1 for 'once' and 2 for 'more than once'.

In wave 4 , the child (aged $\sim 10$ years) self-reported their intake in the face-to-face interview. The question asked was, "Thinking about yesterday, how often did you have...(1) fruit, (2) cooked vegetables, (3) raw vegetables or salad?" For fruit responses, frequency was coded 0 for 'not at all', 1 for 'once' and 2 for 'more than once'. For vegetable responses, frequency was coded 0 for 'not at all', 1 for 'once', 2 for 'twice' and 3 for 'more than twice'.

Responses were summed to calculate a final score for fresh fruit, cooked vegetable and raw vegetable/salad consumption.

Screen time. Children's television and computer use were parent reported at each wave as an indicator of screen time levels. The two questions for each behaviour were, "About how many hours on a typical weekday, would you say the child watches TV or videos at home?" and "About how many hours on a typical weekend day, does the child watch TV or videos at home?" Children's computer use was similarly collected; 'uses computer' was substituted for 'watch TV or videos'.

\section{Data management and analysis}

The dependent variable in this study was change in weight status category. The child's height, weight, sex and age were used to calculate the age-specific and sexspecific z-scores (BMI z-score) according to the WHO Growth Standard for children from birth to 60 months ${ }^{21}$ and Growth Reference for children aged 5-19 years. ${ }^{22}$ The participants were classified into four BMI z-score categories according to the $\mathrm{WHO}^{21}$ cut-off points: overweight (>+1SD, equivalent to BMI $25 \mathrm{~kg} / \mathrm{m}^{2}$ at 19 years), obese ( $>+2 \mathrm{SD}$, equivalent to BMI $30 \mathrm{~kg} / \mathrm{m}^{2}$ at 19 years), thinness $(<-2 \mathrm{SD})$ and severe thinness $(<-3 \mathrm{SD})$. Owing to the small number of participants in the outlying categories, thinness and severe thinness (approximately $1 \%$ of the entire population) were combined with normal weight.

The 'change in weight status' categories were constructed by comparing the weight status at a later data collection wave with that at a previous wave: separately, waves 2, 3 and 4 compared with wave 1 ; wave 3 compared with wave 2; and wave 4 compared with wave 3 with four possible categories at each comparison; changed weight status from normal to overweight/ obese, changed weight status from overweight/obese to normal, remained at a normal weight or remained overweight/obese.

\section{Statistical analysis}

Data were analysed using Stata V.12.0 (StataCorp, College Station, Texas, USA, 2011). In all cases, results were considered statistically significant if $\mathrm{p}<0.05$.

Cross-tabulation was used to show the movement of children between weight status categories over time, while multinomial logistic regression was used to examine the individual-level predictors of change in weight status.

The outcome variable was change in weight status, between normal weight and the combined overweight/ obese category, resulting in a referent group of normal weight to normal weight and three other groups; changed weight status from normal to overweight/obese (incident); changed weight status from overweight/ obese to normal (remission); or remained overweight/ obese (constant). Predictors of change in weight status category were examined between baseline and each of the three subsequent waves (ie, change over 2, 4 and 6 years, respectively). The analysis at each wave included both an unadjusted model that was mutually adjusted for the other behaviours, which included the independent variables only (fruit and vegetable intake, HFF intake, SSB intake, computer use during the week and weekend and television use during the week and weekend) and the second model included independent variables plus covariates (sex, age, ethnicity, SEP and mother's and father's BMI).

\section{RESULTS}

Table 1 presents the demographic characteristics of the children. Of the 4169 participants, $51.3 \%$ were male and the mean age of children at wave 1 was $4.8 \pm 0.2$ years. Almost all children were born in Australia (95.8\%), spoke English at home $(87.5 \%)$ and the majority had parents who were born in Australia. Furthermore, 61.4\% of children lived in metropolitan areas and the remainder lived in non-metropolitan areas. The mean height and weight of the children increased over waves (with age), but the BMI z-scores did not. Overall, the mean BMI $\mathrm{z}$-scores at waves $2(-0.15 ; \mathrm{p}<0.001), 3(-0.06$; $\mathrm{p}=0.012)$ and $4(-0.07 ; \mathrm{p}=0.006)$ were significantly lower than the mean BMI $z$-score at wave 1 . For males, the 


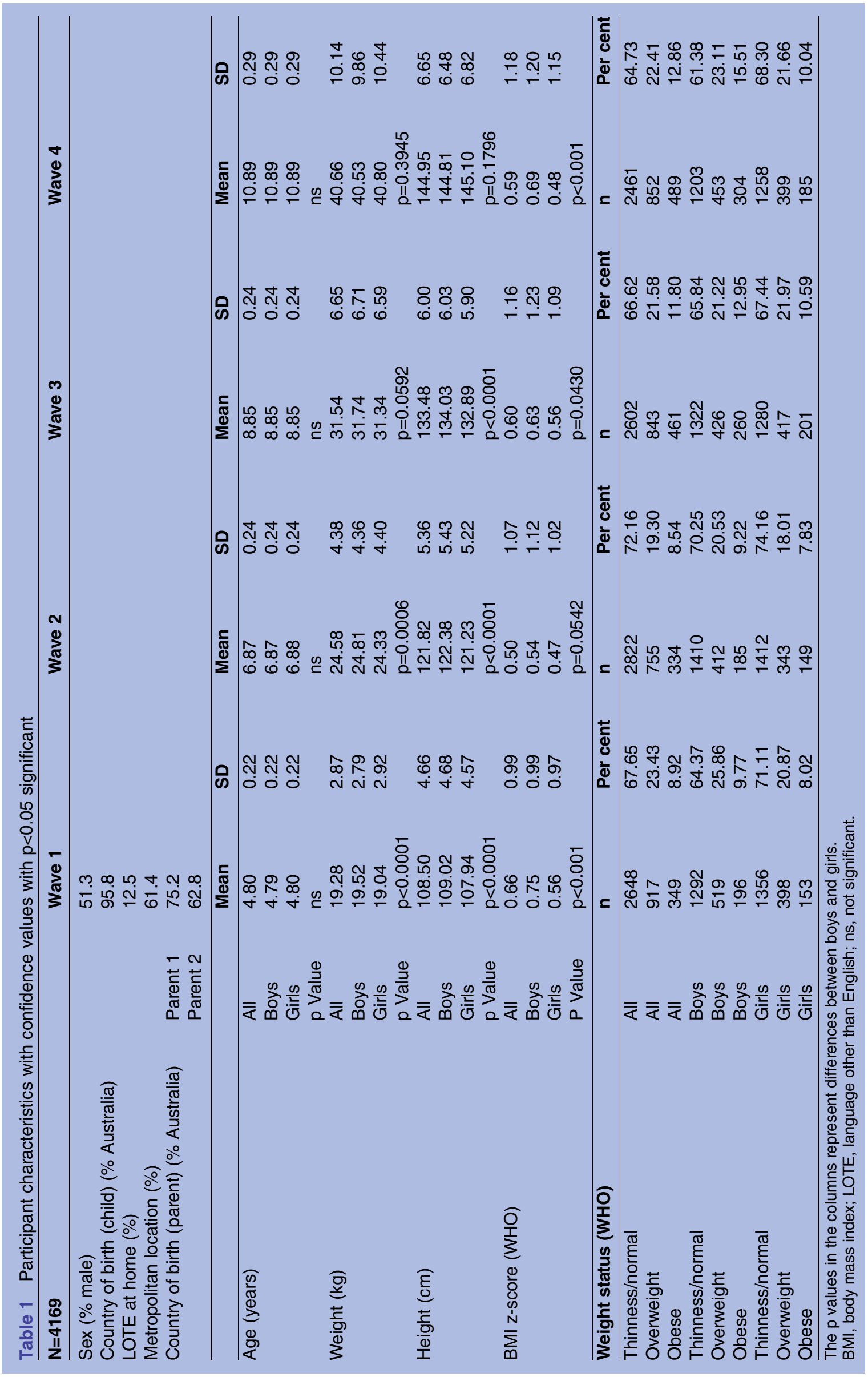




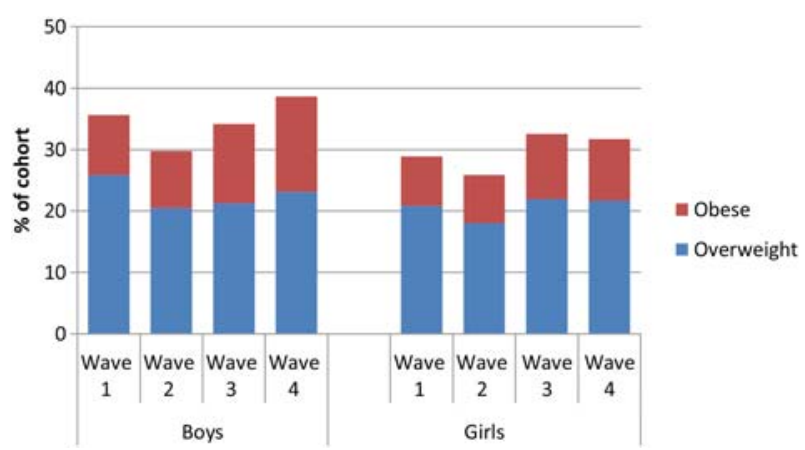

Figure 1 Prevalence of overweight and obesity at each wave of data collection by sex.

mean BMI z-scores at waves $2(-0.22, \mathrm{p}<0.001)$ and 3 $(-0.12, p=0.001)$ were significantly lower than at wave 1 ; however, the mean BMI z-score at wave $4(-0.06$, $\mathrm{p}=0.09$ ) was not different from baseline. For females, the mean BMI z-scores at waves $2(-0.09, \mathrm{p}=0.01)$ and 4 $(-0.08, \mathrm{p}=0.02)$ were significantly lower than at wave 1 ; however, the mean BMI z-score at wave $3(-0.002$, $\mathrm{p}=0.96$ ) was not different from baseline.

Figure 1 shows the percentage of children classified as overweight and obese at each wave, according to sex. From wave 1 to 4 , the number of children who were classified as obese increased significantly $(8.9-12.9 \%$, $\mathrm{p}<0.001)$. Males had a significantly higher prevalence of overweight and obesity compared with females at all waves.

\section{How strongly does overweight and obesity track?}

Children's weight status categories at each wave of data collection were cross-tabulated to examine the proportion of children who changed category between waves of data collection (each 2 years apart). As expected, over short time periods, weight status was relatively stable, while over 6 years (from wave 1 to 4 ), there was a greater degree of change, particularly among those who were overweight at wave 1 (figure 2). Among the children who were normal weight at wave 1 (the 1st cluster of bars on the left of the figure), the vast majority remained in the same weight status category at wave 4 ,

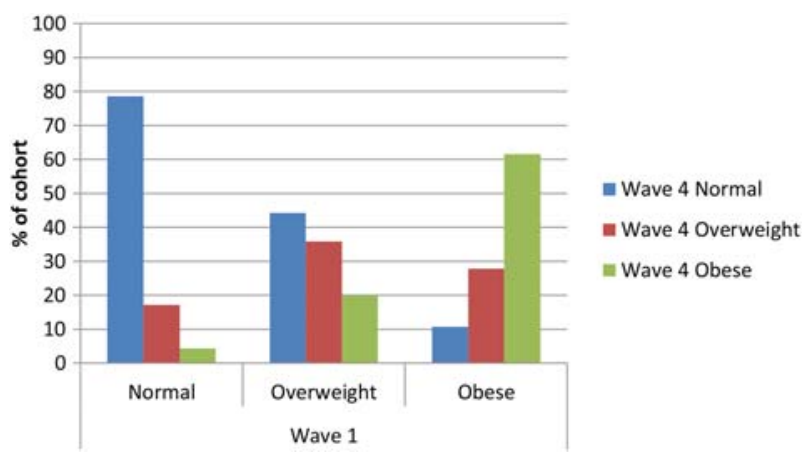

Figure 2 Prevalence of tracking of normal weight, overweight and obesity from wave 1 to 4 . while a small percentage moved into the overweight category. Among those who were overweight at wave 1, however, over $40 \%$ were classified as normal weight 6 years later, while nearly $20 \%$ had become obese. Almost two-thirds of those who were obese at wave 1 remained obese at wave 4 .

What factors influence the stability of weight status?

An unadjusted multinomial regression analysis with weight status being predicted by fruit and vegetable intake, HFF intake, SSB intake, computer use during the week and weekend and television use during the week and weekend found that the relative risk of being in the overweight-obese category compared with the normal weight status category increased significantly with increased television viewing and consumption of SSB at all waves (table 2). Further, in table 2, compared with children who remained in the normal weight status category from wave 1 to 2 , those who were in the overweight-obese category at wave 1 and remained so at wave 2 were more likely to drink SSB and watch television on weekends $(\mathrm{p}<0.05)$.

Table 3 shows results of the adjusted multinomial logistic regression analysis with weight status being predicted by the above behavioural variables, with additional adjustment for age, sex, ethnicity, SEP and mother's and father's BMI. Analyses were also stratified by sex; however, there were very few differences between sexes (data not shown). Overall, there were few significant associations identified between behaviours investigated and the strength of tracking of weight status.

Over 2, 4 and 6 years (table 3), the relative risk of moving into or remaining in the overweight-obese category compared with the normal weight status category increased with increased fruit and vegetable consumption $(\mathrm{p}<0.05)$ in the adjusted model. Over 6 years (wave $1-4)$, compared with children who remained in the normal weight status category, those remaining in the overweight-obese category were more likely to consume SSB $(\mathrm{p}<0.05)$. Moreover, from wave 1 to 3 , the relative risk of progressing into the overweight-obese category compared with remaining in the normal weight status category increased with increased television viewing on weekends $(\mathrm{p}<0.05)$.

Table 4 shows the multinomial logistic regression analysis examining the extent to which SEP predicts weight status stability or change over time. From wave 1 to 2 , the relative risk of remaining in the overweight/obese category compared with the normal weight status category was more than two times greater for the most disadvantaged compared with the least disadvantaged. Between waves 3 and 4, the relative risk of resolving from overweight/obese to normal compared with remaining in the normal weight status category decreased for the most disadvantaged compared with the least disadvantaged. Furthermore, this was particularly evident among females. Analysis of changes between waves 1-3 and waves 1-4 (4 and 6 years, 

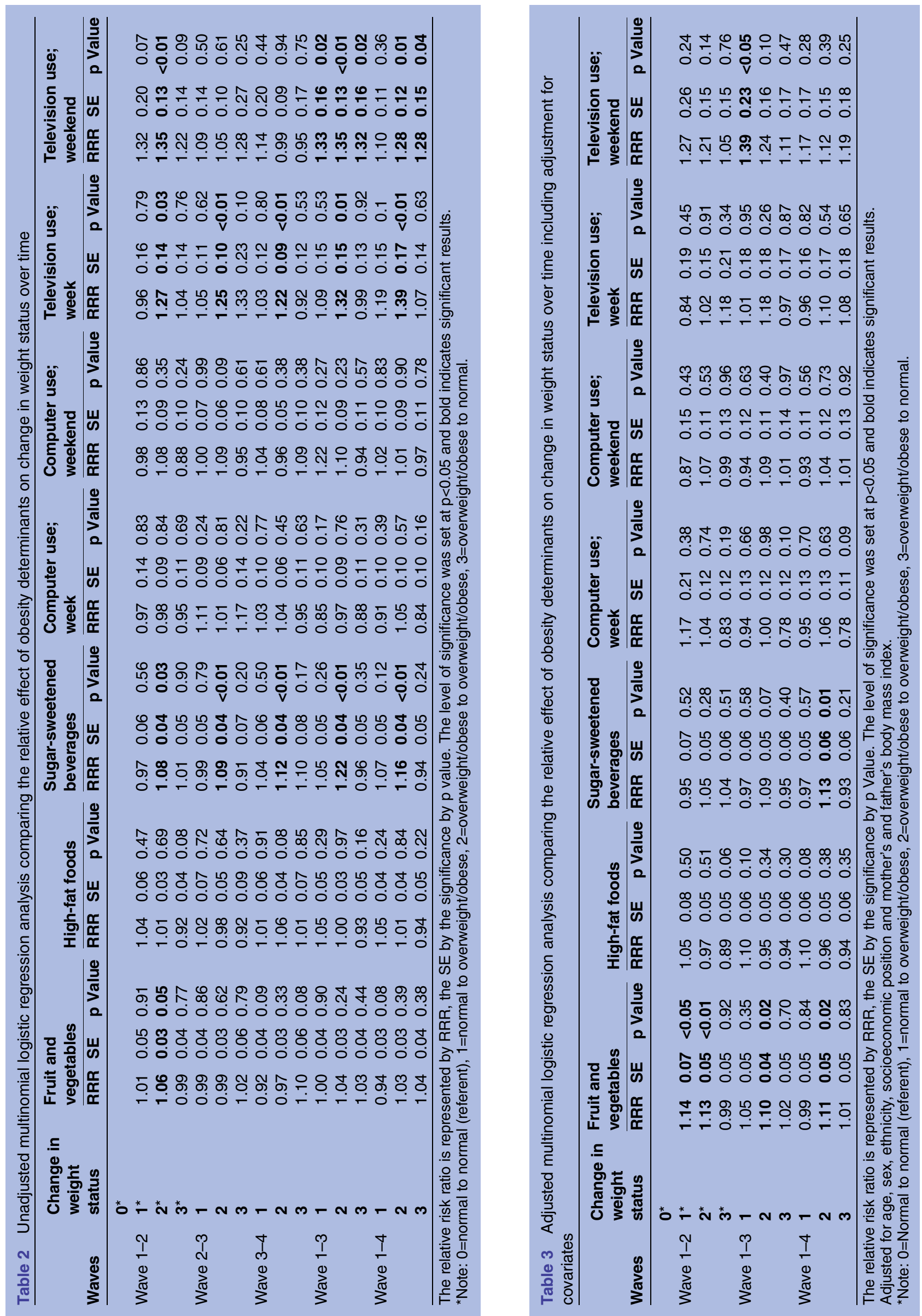
Table 4 Association between SEP and children's weight status categories, by wave

\section{RR for SEP quintile}

\begin{tabular}{|c|c|c|c|c|c|c|c|}
\hline \multirow[b]{2}{*}{ Waves } & \multirow[b]{2}{*}{ SEP quintiles } & \multicolumn{6}{|l|}{ RR for SEP quintile } \\
\hline & & RR (95\% Cl) & p Value & RR (95\% Cl) & p Value & RR (95\% Cl) & p Value \\
\hline \multirow{3}{*}{ Wave 1-2 } & 2nd Quintile & 1.35 (0.80 to 2.28$)$ & 0.26 & $1.02(0.74$ to 1.41$)$ & 0.86 & $0.87(0.60$ to 1.26$)$ & 0.46 \\
\hline & 3rd Quintile & $1.43(0.84$ to 2.43$)$ & 0.19 & $1.33(0.97$ to 1.82$)$ & 0.07 & $0.94(0.65$ to 1.37$)$ & 0.75 \\
\hline & 4th Quintile & $1.82(1.07$ to 3.09$)$ & 0.03 & $1.20(0.85$ to 1.68$)$ & 0.30 & $0.77(0.50$ to 1.17$)$ & 0.22 \\
\hline \multirow[t]{5}{*}{ Wave $1-3$} & \multicolumn{7}{|c|}{ Adjusted $^{*}$ for independent variables and covariates } \\
\hline & 2nd Quintile & $0.98(0.67$ to 1.46$)$ & 0.94 & $0.89(0.65$ to 1.22$)$ & 0.49 & $1.00(0.67$ to 1.49$)$ & 1.00 \\
\hline & 3rd Quintile & $0.81(0.53$ to 1.23$)$ & 0.32 & 0.97 (0.71 to 1.32$)$ & 0.84 & 1.31 (0.89 to 1.92$)$ & 0.18 \\
\hline & 4th Quintile & $1.21(0.80$ to 1.82$)$ & 0.36 & $0.92(0.66$ to 1.30$)$ & 0.65 & $1.12(0.72$ to 1.72$)$ & 0.62 \\
\hline & Most disadvantaged & 1.68 (1.06 to 2.65$)$ & 0.03 & 1.46 (0.99 to 2.13$)$ & 0.05 & $1.43(0.87$ to 2.35$)$ & 0.15 \\
\hline Wave 1-4 & \multicolumn{7}{|c|}{ Adjusted* for independent variables and covariates } \\
\hline
\end{tabular}

respectively) found that the relative risk of moving from normal to overweight/obese and of remaining overweight/obese compared with remaining in the normal weight status category was greater for the most disadvantaged compared with the least disadvantaged. This was significant among girls but not boys.

\section{DISCUSSION}

The purpose of this study was to examine weight status tracking throughout early to middle childhood and the key influencing factors in a representative sample of Australian children. The results suggest that weight status tracks reasonably strongly among Australian children between the ages of 4 and 10 years; key predictive factors include SEP, SSB consumption, television viewing and, counter-intuitively, increased fruit and vegetable consumption, confirming and extending findings from previous local and international studies. $^{6} 1617$ 23-26

Weight status tracking was examined over 2-year, 4-year and 6 -year periods. When classified using internationally defined criteria, over one-third of overweight and obese children resolved to the normal weight status category over 6 years, highlighting that a significant minority of children do slow their weight gain relative to height and experience remission of childhood overweight and obesity. This study was not able to identify whether the remission was due to any deliberate changes aiming to reduce relative weight; however, owing to the lack of effective or widely available treatment options available to children and families in the community, ${ }^{27}$ it is most likely that this is due to progression through normal stages of growth, such as the beginning of the adiposity rebound. ${ }^{28}$
Of those children who were initially normal weight, over the first 2 years of the study, from wave 1 to 2 , almost all (91\%) children remained in the normal weight status category. More than $40 \%$ of overweight children at wave 1 resolved their weight status to normal over the same period, which may be a reflection of children experiencing the adiposity rebound around this age (4-6 years), and the adiposity rebound occurring at an age which is slightly out of alignment with that displayed in the reference standard used to define weight status in this group. ${ }^{28}$ However, $66 \%$ of initially obese children remained obese after 2 years. When the stability of weight status was examined over 4 and 6 years, it was evident that with increasing time between measurements, there was, as expected, a higher percentage of children changing weight status categories. Over 6 years, of those who were normal weight at wave 1 , there were 441 incident cases of overweight $(17 \%)$ and 111 incident cases of obesity $(4.3 \%)$, while $36 \%$ of children who were overweight and $62 \%$ who were obese at wave 1 remained in that category at wave 4 .

The results of this study showed that as SEP decreased, the relative risk of moving from the normal to overweight/obese category or remaining in the overweight/ obese category increased. This is consistent with previous research, ${ }^{12}{ }^{23}{ }^{29}$ highlighting the inverse association between SEP and tracking of overweight and obesity as demonstrated among Australian and American cohorts. Although the evidence in the literature is equivocal about the interaction of SEP and gender in influencing adiposity, ${ }^{30}$ we found a much stronger association among girls than boys. ${ }^{12} 26$

Consistent with previous international studies, ${ }^{6}{ }^{31}$ this study found that an important predictor of childhood 
weight status in this large cohort of Australian children is SSB consumption. The consumption of SSBs among children increased over time. The reasons for this increase could include the increased autonomy children had over discretionary purchases, but it may also be a function of the availability of SSBs in the household and parental role modelling. After adjustments for independent variables and covariates, the association between SSBs and tracking of overweight was only significant when analysed over the full 6 years of the study (wave $1-4)$. The multinomial logistic regression analysis produced few significant results, suggesting that the sensitivity of measures used may have been limited, and that there are probably numerous interacting factors driving the change in weight status among children, including perhaps many small influences that have an additive or multiplicative effect.

The relative risk of remaining in the overweight-obese category compared with the normal weight status category increased significantly with increased television viewing at all waves. The results from the current study suggest that television viewing is positively associated both with the risk of childhood overweight and obesity and with the longitudinal odds of becoming or remaining overweight during the early to middle childhood years. This finding is consistent with the finding from other longitudinal studies. ${ }^{32} 33$

The major strength of this research is that the data are drawn from four recent waves of a large, nationally representative longitudinal cohort of Australian children. The study used high-quality, reliable data collection methods for anthropometric measures, which were collected in person by trained personnel according to best practice protocols. ${ }^{19}$ Further, the study had a high retention rate of participants. Of the 4983 children who participated in the baseline (wave 1) survey, 4169 children completed all four waves of data collection, representing an attrition rate of just $16.3 \%$ over 6 years.

Nonetheless, several considerations must be made before generalising the present findings to the Australian population. First, BMI-based reference standards were used to determine weight status, which may have misclassified some children, especially those who have less severe overweight. ${ }^{34}$ Second, children from disadvantaged areas, non-English speaking backgrounds and single-parent families are somewhat underrepresented in the LSAC cohort, while there was an over-representation of children with mothers with higher education levels (those who had completed year 12 education). There are also a number of difficulties surrounding data collection in relation to diet and activity behaviours and limitations to the accuracy and reliability of reporting, including the social desirability bias, and $24 \mathrm{~h}$ recall data may not represent usual behaviour. The dietary indicators in particular offered a relatively crude representation of consumption patterns. Further, there were only a limited number of dietary indicators; there was no information about total dietary intake; therefore, no adjustment of dietary intake for energy expenditure could be made. This may explain the apparently anomalous association of increased fruit and vegetable consumption with tracking.

To inform future prevention and intervention strategies, this study suggests the importance of focusing on risk factors (SSB, HFF and screen time) of overweight tracking among children of lower SEP. Further research is needed to better understand the apparently anomalous association between higher reported fruit and vegetable intake and increased tracking. Additionally, previous research ${ }^{23}$ has highlighted the importance of examining the underlying factors associated with the apparently greater resilience of children of higher SEP and subsequent decreases in mean BMI. This study extends the work of Jansen et $a l^{23}$ by examining the influence of various dietary indicators (SSB, HFF and fruit and vegetable consumption) and screen time (computer and television use) on weight status trajectories through early to middle childhood. Socioeconomic differences in obesogenic behaviours were not associated with the observed differences in weight status trajectories by SEP. That is, it is not as simple as people of lower SEP 'behaving poorly'; rather, there may be more complex interactions at work. Further research is required to investigate the associations between SEP, sociodemographic predictors and childhood weight status, particularly using more robust and reliable measures of dietary intakes and physical activity and sedentary behaviours.

\section{CONCLUSION}

Future research could aim to better understand overweight and obesity by identifying the timing of onset and predicting factors as well as targeting prevention approaches to children prior to school entry. This study showed that overweight and obesity among Australian children aged 4-10 years is a major public health issue and that weight status tracks strongly throughout the early to middle childhood years in lower SEP children. Significant public health action is required to reduce socioeconomic inequalities and promote healthier behaviours and healthy weight status for all Australian children.

Acknowledgements This study uses unit record data from Growing Up in Australia, the Longitudinal Study of Australian Children. The study is conducted in partnership between the Department of Families, Housing, Community Services and Indigenous Affairs (FaHCSIA), the Australian Institute of Family Studies (AIFS) and the Australian Bureau of Statistics (ABS). The findings and views reported in this study are those of the author and should not be attributed to FaHCSIA, AIFS or the ABS.

Contributors NW led the writing and analysis. MN developed the original idea and plan for the study and contributed to the writing, analysis and interpretation. LM contributed to the analysis. NW, MN, LM and SA contributed to the writing, interpretations of results and reviewed and approved the final manuscript.

Funding SA is supported by funding from an Australian National Health and Medical Research Council/Australian National Heart Foundation Career Development Fellowship (APP1045836). SA is supported by the US National 
Institutes of Health grant titled Systems Science to Guide Whole-ofCommunity Childhood Obesity Interventions (1R01HL115485-01A1). SA and LM are researchers within an NHMRC Centre for Research Excellence in Obesity Policy and Food Systems (APP1041020). MN is supported by funding from the National Heart Foundation of Australia and Deakin University for the Australian Heart Disease Statistics Project (HeartStats).

Competing interests None declared.

Patient consent Parental/guardian consent obtained.

Ethics approval The LSAC study was approved by the Australian Institute of Family Studies Ethics Committee.

Provenance and peer review Not commissioned; externally peer reviewed.

Data sharing statement Access to data from the Longitudinal Study of Australian Children is granted by the Australian Government Department of Social Services.

Open Access This is an Open Access article distributed in accordance with the Creative Commons Attribution Non Commercial (CC BY-NC 4.0) license, which permits others to distribute, remix, adapt, build upon this work noncommercially, and license their derivative works on different terms, provided the original work is properly cited and the use is non-commercial. See: http:// creativecommons.org/licenses/by-nc/4.0/

\section{REFERENCES}

1. Field A, Cook N, Gillman M. Weight status in childhood as a predictor of becoming overweight or hypertensive in early adulthood. Obes Res 2005;13:163-9.

2. Magarey A, Daniels L, Boulton T, et al. Predicting obesity in early adulthood from childhood and parental obesity. Int J Obes Relat Metab Disord 2003;27:505.

3. Reilly JJ, Kelly J. Long-term impact of overweight and obesity in childhood and adolescence on morbidity and premature mortality in adulthood: systematic review. Int J Obes 2011;35:891-8.

4. O'Brien M, Nader PR, Houts RM, et al. The ecology of childhood overweight: a 12-year longitudinal analysis. Int $J$ Obes 2007;31:1469-78.

5. Crawford D, Cleland V, Timperio A, et al. The longitudinal influence of home and neighbourhood environments on children's body mass index and physical activity over 5 years: the CLAN study. Int $J$ Obes 2010;34:1177-87

6. Fiorito LM, Marini M, Francis LA et al. Beverage intake of girls at age 5 y predicts adiposity and weight status in childhood and adolescence. Am J Clin Nutr 2009;90:935-42.

7. Ludwig DS, Peterson KE, Gortmaker SL. Relation between consumption of sugar-sweetened drinks and childhood obesity: a prospective, observational analysis. Lancet 2001;357:505-8.

8. Tam CS, Garnett SP, Cowell CT, et al. Soft drink consumption and excess weight gain in Australian school students: results from the Nepean study. Int J Obes 2006;30:1091-3.

9. Rangan A, Kwan J, Flood V, et al. Changes in 'extra' food intake among Australian children between 1995 and 2007. Obes Res Clin Pract 2011;5:e55-63.

10. Baum CL, Ruhm CJ. Age, socioeconomic status and obesity growth $J$ Health Econ 2009;28:635-48.

11. Valerio G, D'Amico O, Adinolfi M, et al. Determinants of weight gain in children from 7 to 10 years. Nutr Metab Cardiovasc Dis 2006;16:272-8.

12. Balistreri K, Van Hook J. Trajectories of overweight among US school children: a focus on social and economic characteristics. Matern Child Health J 2011;15:610-19.
13. Waters E, Ashbolt R, Gibbs L, et al. Double disadvantage: the influence of ethnicity over socioeconomic position on childhood overweight and obesity: findings from an inner urban population of primary school children. Int J Pediatr Obes 2008;3:196-204.

14. Freedman DS, Khan LK, Serdula MK, et al. The relation of childhood BMI to adult adiposity: the Bogalusa Heart Study. Pediatrics 2005;115:22-7.

15. Matton L, Thomis M, Wijndaele $\mathrm{K}$, et al. Tracking of physical fitness and physical activity from youth to adulthood in females. Med Sci Sports Exerc 2006;38:1114-20.

16. Julia $M$, van Weissenbruch $M$, Prawirohartono $E$, et al. Tracking for underweight, overweight and obesity from childhood to adolescence: a 5-year follow-up study in urban Indonesian children. Horm Res 2008;69:301-6.

17. Hesketh $\mathrm{K}$, Wake M, Waters $\mathrm{E}$, et al. Stability of body mass index in Australian children: a prospective cohort study across the middle childhood years. Public Health Nutr 2004;7:303-9.

18. Soloff C, Lawrence D, Johnstone R. LSAC technical paper No. 1 Sample design. 2005. http://www.growingupinaustralia.gov.au/pubs/ technical/index.htm

19. Daraganova G, Sipthorp M. LSAC technical paper No. 9; Wave 4 weights. 2011. http://www.growingupinaustralia.gov.au/pubs/ technical/index htm

20. Blakemore T, Strazdins L, Gibbings J. Measuring family socioeconomic position. Aust Soc Policy 2009;8:121-68.

21. WHO Multicentre Growth Reference Study Group. WHO Child Growth Standards: length/height-for-age, weight-for-age, weightfor-length, weight-for-height and body mass index-for-age: methods and development. Geneva: World Health Organization, 2006.

22. WHO. WHO Reference 2007; Growth reference data for 5-19 years. Geneva: World Health Organization, 2010.

23. Jansen PW, Mensah FK, Nicholson JM, et al. Family and neighbourhood socioeconomic inequalities in childhood trajectories of BMI and overweight: longitudinal study of Australian children. PLOS ONE 2013;8:e69676.

24. Nichols M, de Silva-Sanigorski A, Cleary J, et al. Decreasing trends in overweight and obesity among an Australian population of preschool children. Int J Obes 2011;35:916-24.

25. Sanigorski AM, Bell AC, Kremer PJ, et al. High childhood obesity in an Australian population. Obesity 2007;15:1908-12.

26. Wake M, Hardy $\mathrm{P}$, Canterford L, et al. Overweight, obesity and girth of Australian preschoolers: prevalence and socio-economic correlates. Int J Obes 2007;31:1044-51.

27. Oude Luttikhuis $\mathrm{H}$, Baur $\mathrm{L}$, Jansen $\mathrm{H}$, et al. Cochrane review: interventions for treating obesity in children. Evid Based Child Health Cochrane Rev J 2009;4:1571-729.

28. Rolland-Cachera M, Deheeger M, Bellisle F, et al. Adiposity rebound in children: a simple indicator for predicting obesity. Am J Clin Nutr 1984;39:129-35.

29. O'Dea JA, Dibley MJ, Rankin NM. Low sleep and low socioeconomic status predict high body mass index: a 4-year longitudinal study of Australian schoolchildren. Pediatr Obes 2012;7:295-303.

30. Shrewsbury V, Wardle J. Socioeconomic status and adiposity in childhood: a systematic review of cross-sectional studies 1990-2005. Obesity 2008;16:275-84.

31. Kudlová E, Schneidrová D. Dietary patterns and their changes in early childhood. Cent Eur J Public Health 2012;20:126-34.

32. Hancox RJ, Milne BJ, Poulton R. Association between child and adolescent television viewing and adult health: a longitudinal birth cohort study. Lancet 2004;364:257-62

33. Davison KK, Marshall SJ, Birch LL. Cross-sectional and longitudinal associations between TV viewing and girls' body mass index, overweight status, and percentage of body fat. $J$ Pediatr 2006;149:32-7.

34. Freedman DS, Sherry B. The validity of BMI as an indicator of body fatness and risk among children. Pediatrics 2009;124:S23-34. 